\title{
Entre a lei de Thirlwall e a hipótese Prebisch-Singer: uma avaliação da dinâmica dos termos de troca em um modelo de crescimento com restrição no Balanço de Pagamentos *
}

\author{
Marwil Dávila-Fernández ** \\ Adriana Amado ${ }^{* * *}$
}

\begin{abstract}
Resumo
Os modelos de crescimento com restrição no balanço de pagamentos (BOPC) podem ser utilizados para capturar importantes insights tanto da tradição keynesiana quanto estruturalista do pensamento econômico. Sugerimos que a Lei de Thirlwall corresponde a uma derivação matemática da regra de Prebisch. Dessa forma, este trabalho se propõe a estreitar a relação entre a Lei de Thirlwall e o pensamento cepalino por meio da inclusão, na primeira, de um componente que capte a hipótese Prebisch-Singer de deterioração dos termos de troca, empregando para tal uma definição de taxa de câmbio real alternativa. Chamamos a expressão final obtida de "regra Prebisch-Thirlwall". Propomonos, ainda, a endogeneizar a taxa de crescimento do produto e da produtividade a partir da combinação de nossa versão da lei de Thirlwall com a lei de Kaldor-Verdoorn.
\end{abstract}

Palavras-chave: Crescimento econômico; Lei de Thirlwall; Hipótese Prebisch-Singer; Cepal; Economia pós-keynesiana.

\section{Abstract \\ Thirlwall's law and the Prebisch-Singer hypothesis: an assessment of the dynamics of terms-of-trade in a balance-of-payments-constraint growth model}

The balance-of-payments-constrained growth models (BOPC) can be used to capture key economic insights into both the Keynesian and structuralist tradition. We suggest that Thirlwall's Law corresponds to a mathematical derivation from Prebisch's rule. Thus, this study aims to develop the relationship between Thirlwall's Law and ECLAC's school of thought, adding a component to the first that captures the Prebisch-Singer hypothesis, employing an alternative definition for the real exchange rate to do so. We call the final expression the Prebisch-Thirlwall rule. Further, we endogenize the output and productivity growth rate by combining our version of Thirlwall's law with the Kaldor-Verdoorn's law.

Keywords: Economic growth; Thirlwall's law; Prebisch-Singer hypothesis; Eclac, Post-Keynesian economics.

JEL E12, O11, O41.

* Trabalho recebido em 14 de novembro de 2013 e aprovado em 8 de dezembro de 2014. Os autores agradecem os comentários e sugestões dos professores Amitava Dutt, Thomas Palley, Joanílio Teixeira, Mauro Boianovsky, Mario Dávila e Elisabet Dávila, bem como as recomendações de dois pareceristas anônimos. Eventuais erros e omissões são de inteira responsabilidade dos autores.

** Mestrando pelo Programa de Pós-Graduação do Centro de Desenvolvimento e Planejamento Regional da Universidade Federal de Minas Gerais (Cedeplar/UFMG), Belo Horizonte, MG, Brasil. E-mail: marwil_davila@hotmail.com.

*** Professora do Departamento de Economia da Universidade de Brasília (UnB), Brasília, DF, Brasil. E-mail: uctpama@unb.br. 


\section{Introdução}

A ideia de que no longo prazo o crescimento econômico é limitado pela emergência de desequilíbrios comerciais tem forte tradição na América Latina (Porcile; Curado; Cruz, 2012). Os trabalhos da Comissão Econômica para a América Latina e o Caribe (Cepal) e, especialmente o trabalho do economista argentino Raúl Prebisch, já apontavam o baixo dinamismo do setor exportador e a elevada propensão a importar como principal limitante do crescimento nas economias periféricas. A escola cepalina do pensamento econômico mostra em seus documentos, especialmente os da década de 50, uma grande preocupação com a relação entre as elasticidades-renda associadas ao comércio exterior, a difusão do progresso técnico e o desenvolvimento econômico em economias periféricas (Prebisch, 1959; Rodríguez, 2009 [2006]).

A literatura pós-keynesiana, por sua vez, desenvolveu uma série de modelos de crescimento demand-side, dentre os quais se sobressaem os chamados balanceof-payments-constrained (BOPC), notadamente representados pela lei de Thirlwall. Sua proposição central está em que, para a maioria dos países, a principal restrição à taxa de crescimento do produto está no balanço de pagamentos, porque ele determina o limite do crescimento da demanda ao qual a oferta pode se adaptar (Thirlwall, 1979; Alonso; Garcimartín, 1999; Thirlwall, 2011).

Embora tenha construído seu modelo de forma aparentemente independente, Thirlwall (1983) menciona as similaridades entre a sua formulação e a de Prebisch. Sugerimos que a Lei de Thirlwall pode ser entendida como uma formalização matemática do pensamento cepalino derivado da regra de Prebisch. Dada sua similaridade, nos perguntamos por que a tese Prebisch-Singer da deterioração dos termos de troca dos produtos primários em relação aos manufaturados não é explicitamente incluída no modelo. Dessa forma, este trabalho se propõe a estreitar a relação entre a Lei de Thirlwall e o pensamento cepalino, mostrando que a taxa de crescimento que equilibra o balanço de pagamentos é composta por um efeito renda - que corresponde à lei de Thirlwall - e um efeito preço - que corresponde explicitamente à hipótese Prebisch-Singer.

Desde sua formulação inicial, os modelos de crescimento BOPC têm evoluído no sentido de incorporar os demais componentes do balanço de pagamentos. O exercício desenvolvido no artigo não é a primeira tentativa de incorporar a dinâmica dos preços neste referencial teórico (Dutt, 2002; 2003; Blecker, 2009; Ros, 2013; Araújo, 2013). Entretanto, nossa proposta é única ao introduzir a hipótese Prebisch-Singer a partir de uma definição alternativa da taxa de câmbio.

São três as principais vantagens da abordagem desenvolvida: (i) a deterioração dos termos de troca passa a ser caracterizada por quebras estruturais 
como sugerido pela evidência empírica; (ii) as quebras estruturais decorrem de diferenças nas estruturas de mercado de bens primários e industriais; (iii) o setor de serviços é introduzido na economia. Os modelos teóricos desenvolvidos por Dutt (2002; 2003), Ros (2013) e Araújo (2013) são compatíveis com uma deterioração contínua dos termos de troca, o que não é corroborado empiricamente. Ademais, a deterioração decorre de diferenças nas elasticidades de comércio exterior, o que corresponde a apenas um dos mecanismos apontados por Prebisch-Singer. Nosso exercício permite explorar um segundo mecanismo, a saber, diferenças nas estruturas de mercado que são captadas por um componente de mark-up.

Inicialmente parece haver existido um receio de incorporar as variações dos termos de troca ao modelo, já que o ajuste do balanço de pagamentos via preços poderia implicar em um não ajuste via renda, desqualificando a lei de Thirlwall. Todavia, ao contrário da hipótese neoclássica, consideramos que a deterioração dos termos de troca dos produtos primários em relação aos manufaturados pode reduzir a taxa de crescimento compatível com o equilíbrio no balanço de pagamentos. A evidência empírica não dá suporte à visão neoclássica, como mostrado por Alonso e Garcimartin (1999).

Os modelos analíticos de inspiração pós-keynesiana assumem que o crescimento de longo prazo é endógeno à operação do sistema econômico. Isso significa que o crescimento do produto e da produtividade do trabalho não podem ser tratados como variáveis exógenas (Oreiro, 2011). Assim, endogeneizamos a taxa de crescimento do produto e da produtividade por meio da combinação de nossa versão da lei de Thirlwall com a lei de Kaldor-Verdoorn. A possibilidade de incluir causação cumulativa na tradição BOPC tem sido recentemente explorada por autores como Blecker (2009), Amitrano (2013) e Araújo (2013). Todavia, nosso exercício de modelagem difere das iniciativas anteriores na medida em que a relação entre a restrição externa e a lei de Kaldor-Verdoorn não é obtida por meio dos preços, e sim da razão das elasticidades de comércio exterior, como mostraremos adiante.

O trabalho estrutura-se em quatro seções além desta introdução. Na seção 2, fazemos uma revisão dos principais conceitos por trás do pensamento cepalino de crescimento econômico, dando ênfase especial às ideias desenvolvidas por Prebisch e à hipótese Prebisch-Singer de deterioração dos termos de troca. A seção seguinte apresenta o modelo de crescimento com restrição no balanço de pagamentos, do qual deriva a lei de Thirlwall, relacionando-o com o pensamento cepalino. Na seção 4 , apresentamos nossa proposta de acrescentar um componente que capte a tese Prebisch-Singer de deterioração dos termos de troca, empregando uma definição alternativa para a taxa de câmbio real. Chamamos a expressão final obtida de "regra Prebisch-Thirlwall". Por fim, na seção 5 endogeneizamos a taxa de crescimento do produto e da produtividade combinando nossa versão da lei de Thirlwall com a lei de Kaldor-Verdoorn. A última seção traz as considerações finais. 


\section{$2 \mathrm{O}$ estruturalismo latino-americano e as restrições sobre o comércio exterior}

A ideia de que no longo prazo o crescimento econômico é limitado pela emergência de desequilíbrios comerciais tem forte tradição na América Latina (Porcile; Curado; Cruz, 2012). Dentro da escola cepalina do pensamento econômico, os nomes de Raúl Prebisch, Juan Noyola e Celso Furtado se destacam por terem trabalhado as implicações da restrição externa sobre o crescimento. Apesar de haver importantes diferenças entre suas formulações, um elemento comum está no compartilhamento da perspectiva estruturalista do desenvolvimento (Boianovsky; Sólis, 2014). Nesta seção buscaremos sintetizar o enfoque estruturalista e as considerações feitas por Prebisch a respeito das restrições sobre o comércio exterior.

\subsection{O estruturalismo latino-americano}

Os trabalhos incluídos sob a designação comum de "estruturalistas" compartilham certas posições metodológicas que operam como base essencial de suas contribuições analíticas (Rodríguez, 2009 [2006]). Seu método leva especialmente em conta as características reais das situações analisadas e sua dependência de fatores estruturais historicamente determinados (Bielschowsky, 2009). O ponto de partida de nossa análise - e também o que norteará a descrição desta escola do pensamento - está em sua compreensão do processo de desenvolvimento econômico.

O desenvolvimento é entendido, desde um enfoque estritamente econômico, como o aumento contínuo e sustentado do produto e da dotação de capital por trabalhador que se expressa no aumento do bem estar material. Esse processo, por sua vez, é impulsionado pelo progresso técnico e deve ser acompanhado necessariamente de mudanças na estrutura produtiva e de demanda da economia (Furtado, 2009 [1961]; Rodríguez, 2009 [2006]). Podemos representar a definição acima da forma como segue. Seja a produtividade média da economia $\bar{q}$, dada por:

$$
\bar{q}=\sum_{1}^{n} \theta_{i} q_{i}
$$

Em que $\theta_{i}$ corresponde ao peso de cada setor da economia e $q_{i}$ define a produtividade setorial. Derivando essa expressão em relação ao tempo, temos que:

$$
\dot{\bar{q}}=\sum_{1}^{n} \theta_{i} \dot{q}_{l}+\sum_{1}^{n} \dot{\theta}_{l} q_{i}
$$

A expressão acima permite captar os dois componentes fundamentais da abordagem estruturalista do desenvolvimento. O primeiro coloca variações da produtividade média da economia como resultado de variações das produtividades setoriais. Mudanças em $q_{i}$ levam a alterações em $\bar{q}$ para $\theta_{i}$ constante. $\mathrm{O}$ segundo 
componente, no entanto, mostra que mudanças na composição setorial da economia $\left(\theta_{i}\right)$ também levam a alterações da produtividade média $(\bar{q})$. A transferência de trabalhadores de setores de baixa produtividade para setores de elevada produtividade permite aumentar a produtividade média da economia. Dessa forma, o componente estrutural multissetorial adquire grande importância, contrastando com os modelos de crescimento neoclássicos de apenas um setor.

O subdesenvolvimento, por sua vez, é visto como um estado específico de certas economias e que não pode ser estudado como uma simples fase do processo de desenvolvimento, na medida em que ambos correspondem a aspectos distintos de um mesmo processo histórico ligado à criação e difusão da tecnologia no pósrevolução industrial (Furtado, 2009 [1961]; Rodríguez, 2009 [2006]). Ele é caracterizado por uma profunda heterogeneidade estrutural produtiva e distributiva. Assim, a combinação de uma distribuição bastante desigual da renda e o convívio lado a lado de setores de elevada produtividade com setores de baixa produtividade é observada nos países nessa condição.

As definições acima apresentadas nos permitem introduzir um último elemento de vital importância no pensamento estruturalista cepalino: o sistema centro-periferia. De acordo com Cimoli e Porcile (2013), o pensamento cepalino está baseado na percepção de que o sistema internacional é formado por dois polos, o centro (norte) e a periferia (sul), cujas economias são estruturalmente diferentes. Embora autores como Celso Furtado prefiram evitar essa terminologia ${ }^{1}$, clara está a contraposição existente entre os países desenvolvidos, situados como centrais e subdesenvolvidos, ocupando a posição periférica.

Os centros se identificam como as economias possuidoras das técnicas mais avançadas de produção alcançando, desse modo, maiores níveis de produtividade do trabalho e uma maior homogeneização de sua estrutura produtiva e de demanda. A periferia, em contrapartida, é formada por economias atrasadas do ponto de vista tecnológico e organizacional, além de uma marcante heterogeneidade estrutural. Essa heterogeneidade fica evidente na persistência da dualidade entre o setor atrasado rodeado por ilhas de modernidade e na incompatibilidade entre geração e adoção de tecnologias.

\subsection{As restrições sobre o crescimento e a hipótese Prebisch-Singer}

O interesse inicial de Prebisch, ao estudar a dinâmica do comércio exterior latino-americano, estava em explicar o mecanismo por trás dos ciclos econômicos nessas economias (Boianovsky; Sólis, 2014). Efetivamente, o multiplicador de comércio de Harrod é utilizado para distinguir seus efeitos no centro e na periferia.

(1) Celso Furtado utiliza o termo "Economias dependentes" (Boianovsky, 2010) para diferenciar economias tecnologicamente líderes das atrasadas e, desse modo, dependentes das primeiras. 
No entanto, sua análise não se limita aos ciclos de negócios, sendo estudadas as repercussões do comércio internacional sobre o crescimento de longo prazo e o comportamento dos preços (Rodríguez, 2009 [2006]).

Observa-se que a pauta de comércio mundial reflete a posição de uma economia na dinâmica centro-periferia. Os países do centro, por serem líderes em $\mathrm{P} \& \mathrm{D}$, exportariam produtos industrializados de maior valor agregado e intensidade tecnológica. Os países da periferia por sua vez, ao ocupar posição marginal em termos de inovação, exportariam produtos primários com baixo valor agregado (Prebisch, 1959; Prebisch, 1963; Sai-Wing Ho, 2012). A especialização na periferia implica que o ritmo de expansão da sua produção é limitado por margens que, se excedidas, levariam à deterioração dos termos de troca (Rodríguez, 2009 [2006]).

Considera-se que o crescimento da renda interna na periferia é restringido pela elasticidade-renda das importações na medida em que há um limite de oferta de divisas com o qual ela pode contar para satisfazer suas necessidades de importar. Prebisch $(1949,1959)$ define, então, o desequilíbrio estrutural ${ }^{2}$ como o resultado de um crescimento da renda que leva a um aumento das importações acima do permitido pelas exportações. De acordo com Rodríguez (2009 [2006]) em sua análise do pensamento estruturalista, o desequilíbrio na balança comercial constitui dessa forma a chave dos problemas de desequilíbrio externo, marcados pela alternância de fases de bonança e escassez de divisas.

Mas, o que diferenciaria os produtos industriais dos primários? Duas explicações são dadas para essa pergunta. A primeira delas está relacionada a diferenças nas suas elasticidades-renda. Os produtos primários teriam elasticidaderenda menor que a unidade devido ao fato de que o progresso técnico reduz a demanda por matérias primas substituindo-as por sintéticos. Observa-se, ademais, uma saturação da demanda por alimentos básicos dentro do postulado pela Lei de Engel. Esses fatores seriam agravados por uma menor taxa de crescimento demográfico nos centros. Contrariamente, a elasticidade-renda dos produtos manufaturados seria maior que a unidade, já que esses produtos estão na fronteira tecnológica.

Prebisch (1959) constrói um exemplo numérico ilustrando os efeitos da restrição externa sobre o crescimento econômico. Como hipótese simplificadora, assume-se que só existe 1 país no centro e 1 na periferia. Se na economia central a taxa de crescimento do produto for de $3 \%$ e a elasticidade renda das importações for 0.80, então as importações do centro poderiam crescer a uma taxa de $2.4 \%$. (3x0.80). Por outro lado, suponhamos que a elasticidade da demanda por produtos industriais

(2) O termo "desequilíbrio estrutural" foi introduzido pela primeira vez por Furtado e Noyola em um documento da Cepal da década de 1950, não tendo sido utilizado inicialmente por Prebisch. Ele passa a empregá-lo apenas na década de 1960 (Boianovsky; Sólis, 2014). 
da periferia seja igual a 1.3. Para que sua taxa de crescimento mantenha o equilíbrio no BP, ela não pode ser superior a $1.84 \%$ (2.4 : 1.3). Se a economia periférica crescer à mesma taxa do centro, suas exportações teriam que crescer à taxa de $3.9 \%$ para manter o BP equilibrado, valor bem acima do que a demanda do centro pelas suas exportações. Em termos matemáticos, temos:

$$
\hat{y}=\frac{\hat{x}}{\pi}
$$

em que $\hat{y}$ é a taxa de crescimento do produto, $\pi$ é a elasticidade renda das importações e $\hat{x}$ corresponde à taxa de crescimento das exportações.

Para manter o balanço de pagamentos equilibrado, a taxa de crescimento das importações não pode ser superior a $\hat{x}$. Como notado por Cimoli e Porcile (2013), Boianovsky e Sólis (2014) e o próprio Thirlwall (1983), a expressão final é precisamente equivalente à lei de Thirlwall. A evidência empírica a favor deste argumento se confunde com o suporte encontrado à lei de Thirlwall, já que ambas as formulações tratam das diferenças nas elasticidades-renda dos diversos produtos comercializáveis, e será mais bem explorada na próxima seção.

A segunda explicação para a diferenciação entre os produtos primários e industriais ficou conhecida na literatura como a hipótese Prebisch-Singer da deterioração dos termos de troca. Argumenta-se que existe uma tendência secular de deterioração dos termos de troca em favor dos bens industrializados e em contra dos bens primários. Tradicionalmente, são apontados quatro fatores responsáveis por esse fenômeno: (i) Existência de poder de mercado no setor industrial contrastando com mercados competitivos no setor de commodities (Singer, 1950; Mollic et al., 2008); (ii) Pressão resultante da diferença de elasticidades-renda, demanda dos produtos manufaturados e primários (Prebisch, 1963; Dutt, 2002); (iii) Distribuição desigual de capital humano e conhecimento (Ocampo; Parra, 2003); (iv) Assimetrias no mercado de trabalho entre o centro e a periferia (Prebisch, 1963; Ocampo; Parra, 2010).

Singer (1950) foi o principal defensor do primeiro argumento enquanto que os trabalhos de Prebisch centraram-se no último. Este último distingue-se dos demais, já que se aplicaria a todos os bens produzidos pela periferia, não se restringindo aos produtos primários. A ideia central contida no trabalho de Singer é bastante intuitiva. Assumindo que o progresso técnico se concentra na atividade industrial, este permitiria às firmas do centro possuir poder de monopólio por um espaço de tempo, o que não ocorreria na atividade primária. Prebisch, por sua vez, considera que a relativa lentidão com que cresce a procura mundial de produtos primários associada à existência de um elevado excedente populacional na periferia, geraria uma pressão para baixo sobre os salários que, por sua vez, se traduziria na referida deterioração. 
No modelo neoclássico de comércio exterior, qualquer fator que aumente a oferta de um determinado bem resulta em uma redução de seu preço relativo. Desse modo, em países capazes de influenciar os preços internacionais, o progresso técnico nas indústrias exportadoras levaria a uma deterioração dos termos de troca. Essa posição destoa da hipótese Prebisch-Singer em que, dadas as diferenças na estrutura do mercado de bens e de trabalho entre o centro e a periferia, o progresso técnico leva a uma redução dos preços apenas no segundo grupo.

Embora o tema seja controverso, existe uma vasta gama de trabalhos dentro da literatura de crescimento dando suporte à tese Prebisch-Singer. Antes, é preciso fazer alguns comentários a respeito de como os preços de produtos industriais são medidos na literatura empírica. Se os preços utilizados nos estudos não separam mudanças de preços puros de mudanças que se originam de melhoras na qualidade dos produtos, então os testes podem não estar captando mudanças de preço, e sim, diferenciação de produtos. São duas as metodologias utilizadas pelos trabalhos empíricos na construção desses índices, a saber, o tradicional deflator sobre o valor unitário exportado (MUV) e o deflator sobre o valor adicionado (MVA).

De acordo com Harvey et al. (2010), a utilização do MVA possui três vantagens sobre o MUV: (i) omite a influência de produtos intermediários; (ii) permite mudanças na composição e (iii) captura, em certo grau, impactos do progresso técnico. Uma mudança na composição das exportações em favor de produtos eletrônicos, por exemplo, artificialmente aumentaria o MUV, mesmo que os preços se mantenham inalterados. Todavia, é preciso deixar claro que mesmo o deflator sobre o valor adicionado não está livre de problemas de mensuração, na medida em que tampouco permite captar plenamente os efeitos do progresso técnico. Em nossa revisão da literatura, apenas os trabalhos de Harvey et al. (2010) e Arezky et al. (2013) utilizam o MVA.

Thirlwall e Bergevin (1985) examinam o comportamento dos preços dos produtos primários em relação aos manufaturados para o período 1954-1982. Os autores não apenas confirmam a deterioração, como também mostram que as oscilações nos preços são maiores para os produtos primários. De todo modo, Grilli e Yang (1988) são apontados como a primeira referência mais sólida no tema e a série temporal então construída é utilizada como padrão na maioria dos trabalhos posteriores na área. Os autores construíram índices de preços abarcando os anos de 1900-1986 e encontraram uma tendência de deterioração de $0.6 \%$ ao ano.

Reinhart e Wickham (1994), usando dados trimestrais para o período que compreende os anos de 1957 a 1993, indicam que a fraqueza dos preços das commodities é secular e sugerem a necessidade para países primário-exportadores de se concentrarem na diversificação das exportações. Os autores encontram, ainda, evidência de uma maior volatilidade dos preços desses produtos. 
Ocampo e Parra (2003) analisam a evolução dos termos de troca dos produtos primários durante o século XX e encontram uma deterioração não contínua de até $60 \%$ no período. Ocampo e Parra (2010) estendem o exercício anterior e examinam a evolução dos termos de troca internacionais de commodities e manufaturas desde 1860. Os autores mostram que houve uma melhora dos termos de troca em favor dos bens primários entre o fim do século XIX e inícios do século XX. No entanto, durante o restante do século XX, observa-se uma tendência à sua deterioração, especialmente a partir da década de 1970. Na primeira década do século XXI, registra-se uma melhora dos termos de troca que, no entanto, de longe não reverte a tendência secular.

Utilizando uma base de dados para o período 1900-1998, Zanias (2005) mostra que o preço relativo dos produtos primários caiu para cerca de $1 / 3$, com choques estruturais e de forma não gradual, como implícito em tendência determinística ou estocástica. São identificadas duas quebras estruturais, a primeira em 1920 e a segunda em 1984, que levaram ao declínio dos preços relativos dos produtos primários, não podendo ser rejeitada a tese de Prebisch-Singer em relação à direção do movimento dos termos de troca no longo prazo. Na mesma direção, Bunzel e Vogelsang (2005) encontram suporte empírico para a hipótese de deterioração dos termos de troca a partir da construção de um índice dos termos de troca líquidos para o período de 1900-1995.

Serrano e Pinilla (2011) analisam a evolução dos termos de troca de 56 produtos agrícolas e alimentícios internacionalmente transacionáveis na segunda metade do século XX. Utilizando um novo método econométrico para séries de tempo, foram analisadas quebras estruturais em séries não estacionárias, com os anos em que ocorreram os choques aparecendo de forma endógena no modelo. Encontrase que, em geral, produtos menos elaborados sofreram uma forte queda nos preços reais, bem mais do que registrado em índices agregados. Apenas produtos com elevada elasticidade renda ou difíceis de serem substituídos por sintéticos tiveram uma melhora nos termos de troca. A evidência apresentada também dá suporte a uma deterioração não contínua e em estágios.

Mollic et al. (2008), avaliando os preços relativos dos produtos primários para a economia norte-americana, observam uma tendência negativa significativa entre 1947-1998. Os autores não apenas encontram que a evidência internacional da deterioração dos termos de troca favorece a hipótese de Prebisch-Singer, como também que, assumindo que a globalização torne as economias mais parecidas à norte-americana, a deterioração persiste e não parece poder ser revertida pela integração econômica.

Em um esforço bastante ambicioso, Harvey et al. (2010) constroem um painel formado pelos preços de 25 commodities primárias desde 1650 e testam a 
presença de tendência linear e tendência com quebra estrutural. Os preços de onze produtos apresentaram evidência robusta de uma deterioração em relação às manufaturas. Commodities como o café apresentaram deterioração de $0.77 \%$ ao ano por aproximadamente 300 anos. A conclusão dos autores é que a evidência empírica dá suporte à hipótese Prebisch-Singer.

Em uma contribuição semelhante, Arezkiet al. (2013) reexaminam o comportamento dos preços de 25 produtos primários em relação aos manufaturados utilizando series a partir do século XVII. Os resultados apontam para a existência de uma tendência negativa dos termos de troca em contra das commodities primárias. Além disso, encontra-se que os preços destas são mais voláteis e que dita volatilidade tem aumentado nos últimos anos.

Esta seção foi dedicada à apresentação das principais diretrizes do pensamento estruturalista cepalino e de pontos centrais do trabalho do economista argentino Raúl Prebisch. Como mostrado, há uma clara preocupação com a relação entre crescimento econômico e o desempenho da balança comercial, seja via renda ou via preços. Atenção especial foi dada à evidência empírica existente a favor da tese Prebisch-Singer de deterioração dos termos de troca, dado que ela parece ter sido ignorada por boa parte da literatura de crescimento. Essa marginalização nos parece um equívoco, dado o abundante suporte empírico existente em seu favor, embora não em seus termos originais.

\section{0 modelo de Thirlwall e seus principais desdobramentos}

A ênfase na demanda como motor do sistema econômico, enquanto que diferenças nas taxas de crescimento entre os diversos países seriam fruto de diferenças em seu ritmo de expansão, não é nova na literatura, sendo trabalhada por economistas renomados como Kaldor, Prebisch, Thirlwall e McCombie. A tradição keynesiana considera que o lado da demanda importa na determinação da trajetória de crescimento da economia tanto de curto prazo quanto de longo prazo (Libânio, 2009).

A hipótese fundamental dos modelos chamados balance-of-paymentsconstrained é que o balanço de pagamentos no longo prazo deve estar equilibrado. Diante da impossibilidade do financiamento contínuo dos desequilíbrios no balanço de pagamentos (BP), ocorre um ajuste da demanda agregada que restringe sua expansão e, por sua vez, o crescimento (Romero; Silveira; Jayme Jr., 2011; Setterfield, 2011; McCombie, 2011). O crescimento é demand-led no sentido de que qualquer efeito no lado da oferta sobre o crescimento é necessariamente mediado por um efeito específico sobre a elasticidade renda da demanda (Cimoli; Porcile, 2013).

À medida que uma dada economia cresce, sua demanda por importações também acompanha essa expansão. Esse acréscimo de importações é financiado na 
forma de um aumento das exportações ou de uma maior entrada de capitais. Caso a taxa de crescimento das exportações, que depende da renda externa, não consiga acompanhar a taxa de crescimento das importações, sua diferença deverá ser preenchida via financiamento externo. No entanto, a impossibilidade de financiar indefinidamente esses déficits provoca um ajuste real na economia, restringindo a taxa de crescimento do produto. $\mathrm{O}$ balanço de pagamentos estabelece um limite ao ritmo de expansão da demanda que limita, por consequência, o crescimento da economia.

Neste trabalho assumimos que, para a maioria dos países, a principal restrição à taxa de crescimento do produto está no balanço de pagamentos porque ele determina o limite do crescimento da demanda à qual a oferta pode se adaptar (Thirlwall; Hussain, 1982; Alonso; Garcimartín, 1999; Thirlwall, 2011). Contudo, seguindo a tradição heterodoxa tanto do pensamento pós-keynesiano quanto cepalino, reconhecemos que o desempenho do BP e o padrão de especialização do comércio exterior dependem, por sua vez, de fatores estruturais historicamente determinados (Bielschowsky, 2009).

O modelo canônico de Thirlwall (1979) assume que o desempenho do balanço de pagamentos equivale ao da balança comercial. Dessa forma, podemos sumarizá-lo em três equações:

$$
\left\{\begin{array}{l}
X=(1 / E)^{\varphi} Z^{\Phi} \\
M=(E)^{\beta} Y^{\pi} \\
X=E M
\end{array}\right.
$$

Onde $X$ representa as exportações, $M$ as importações, $Z$ a renda mundial, $Y$ a renda doméstica e $E$ corresponde à taxa de câmbio real. Finalmente $\varphi, \beta<0$ e $\Phi, \pi>0$ correspondem às elasticidades preço-demanda e renda-demanda das exportações e importações, respectivamente. A equação (3.1c) nos dá a condição de equilibro no BP. Logaritmando e derivando no tempo:

$$
\left\{\begin{array}{l}
\hat{x}=-\varphi(\hat{e})+\Phi \hat{z} \\
\widehat{m}=\beta(\hat{e})+\pi \hat{y} \\
\hat{x}=\hat{e}+\widehat{m}
\end{array}\right.
$$

em que o sobrescrito caracteriza a taxa de variação da variável em questão.

Substituindo (3.2a) e (3.2b) em (3.2) e isolando $\hat{y}$, obtemos a taxa de crescimento compatível com o equilíbrio no balanço de pagamentos:

$$
\hat{y}=\frac{-(1+\varphi+\beta) \hat{e}+\Phi \hat{z}}{\pi}
$$

Alonso e Garcimartín (1999) argumentam que não há evidência significativa de que variações nos preços relativos ajustariam o BP. Na versão neoclássica, a relação de causalidade da equação (3.3) é dada por $\hat{e}=\frac{\Phi \hat{z}+\pi \hat{y}}{(1+\varphi+\beta)}$, onde, assumindo 
preços flexíveis no longo prazo, $\hat{e}$ se ajustaria a eventuais desequilíbrios no BP. Entretanto, como apresentado pelos autores, essa posição não seria corroborada empiricamente. Se existe ajuste, ele não é significativo ou não alivia a restrição, pelo menos em um primeiro momento (McCombie, 2011; Thirlwall, 2011). Tomando então como verdadeira a paridade do poder de compra (PPP), obtemos a regra simples de Thirlwall:

$$
\hat{y}=\frac{\Phi}{\pi} \hat{z}
$$

Dada a equação (3.4), o crescimento de longo prazo de uma economia é diretamente proporcional ao produto entre variação da renda externa e à razão entre as elasticidades renda-demanda das exportações e importações. O crescimento da renda interna é restringido pela elasticidade-renda das importações na medida em que há um limite de oferta de divisas com o qual essa economia pode contar para satisfazer suas necessidades de importar. Isso significa que quanto maior a razão entre as elasticidades renda do comércio exterior, menor a restrição ao crescimento por parte do BP. Em economias primário-exportadoras, a tendência de crescimento é menor que dos países industrializados na medida em que essa razão é menor para as primeiras $^{3}$ (Gouvêa; Lima, 2010, 2013). O gap de renda entre países desenvolvidos e subdesenvolvidos deriva desta restrição.

Krugman (1989), assumindo paridade do poder de compra (PPP), desenvolve, de forma independente, um modelo em que $\frac{\hat{y}}{\hat{z}}=\frac{\Phi}{\pi}$, sendo que as elasticidades renda das exportações e importações se ajustariam às diferenças entre as taxas de crescimento. A chamada regra de $45^{\circ}$ de Krugman inverte a relação de causalidade proposta por Thirlwall e sugere que países com elevadas taxas de crescimento se especializariam na produção de bens com maior elasticidade renda. Enquanto a taxa de crescimento da economia seria determinada por fatores do lado da oferta, a demanda aparece como simples variável de ajuste. Essa proposição, no entanto, não se sustenta seja empiricamente ou por desconsiderar o efeito que a taxa de crescimento tem sobre os próprios ganhos de produtividade (McCombie, 2011). Araújo e Lima (2007) mostram ainda, em sua versão do modelo de Thirlwall, que o ajuste proposto por Krugman não é possível por não explicar a possibilidade de mudança estrutural, como veremos adiante.

Considerando que um país comercializa com uma gama variada de outras nações, Nell (2003) desagregou as elasticidades renda das exportações e importações para cada parceiro comercial. Esta modificação é bastante conveniente na medida

(3) Gouvêa e Lima (2010) estimaram a elasticidade-renda da pauta exportadora brasileira por setores para o período 1962-2006, o que nos permite uma comparação bastante útil. Os coeficientes estimados para os produtos primários, intensivos em mão de obra/recursos naturais e de baixo conteúdo tecnológico foram de 1.14, 1.35 e 1.53 , respectivamente. Já os setores de intensidade tecnológica média e alta apresentaram elasticidades de 2.16 e 2.96. 
em que permite aproximar melhor o modelo à realidade. Desse modo, a lei de Thirlwall assume o seguinte formato:

$$
\hat{y}=\frac{\sum_{i=1}^{n} \theta_{x, n} \Phi_{n}}{\sum_{i=1}^{n} \theta_{m, n} \pi_{n}} \hat{z}
$$

em que $\theta_{x, n}$ e $\theta_{m, n}$ correspondem ao peso das exportações e importações ao país $n$ nas exportações e importações totais, respectivamente.

Procurando incorporar o elemento "mudança estrutural" ao modelo original, Araújo e Lima (2007) derivam a partir de uma abordagem pasinettiana multissetorial, a taxa de crescimento compatível com o equilíbrio no BP. A expressão final obtida, e que ficou conhecida de Lei de Thirlwall multissetorial, indica que a taxa de crescimento da renda per capita é diretamente proporcional à taxa de crescimento das exportações ponderada pela razão entre as elasticidades renda-demanda setoriais das exportações e importações. Matematicamente, temos:

$$
\hat{y}=\frac{\sum_{i=1}^{n} \theta_{x, n} \Phi_{n}}{\sum_{i=1}^{n} \theta_{m, n} \pi_{n}} \hat{z}
$$

em que $\theta_{x, p}$ e $\theta_{m, p}$ correspondem ao peso de cada setor no volume total de exportações e importações, respectivamente. Enquanto as elasticidades permanecem constantes, mudanças no crescimento podem provocar mudança estrutural, dada a evolução das preferências de acordo com a lei de Engel. Mesmo que o crescimento do restante do mundo seja próximo a zero, a transferência de trabalhadores de setores de menor elasticidade-renda para setores de maior elasticidade possibilita aumentar a taxa de crescimento compatível com o BP. Mudanças nos componentes de demanda alteram a participação dos diversos setores no comércio exterior e têm impacto significativo em termos de crescimento.

A formulação originalmente desenvolvida por Thirlwall também evoluiu no sentido de incorporar os demais elementos do balanço de pagamentos. Thirlwall e Hussain (1982), Barbosa-Filho (2001) e Moreno-Brid (2003) adicionaram o fluxo de capitais, enquanto que Alleyne e Francis (2008) acrescentaram a conta de transferências ${ }^{4}$. Apesar de reconhecer a importância de seus trabalhos, para efeito de simplificação nos limitaremos em nosso exercício de modelagem à equivalência entre a balança comercial e o balanço de pagamentos.

Entre as principais críticas dentro da própria literatura pós-keynesiana à abordagem BOPC, Palley (2002) chama a atenção para o fato de o paradigma keynesiano ter caído na armadilha de não modelar apropriadamente o lado da oferta. Embora seja verdade que a razão das elasticidades de comércio exterior capte indiretamente aspectos do lado da oferta, ela não é explicitamente modelada. No

(4) Para uma revisão completa das principais variações da lei de Thirlwall e do amplo suporte empírico a seu favor, ver Thirlwall (2011) 
longo prazo, as taxas de crescimento da oferta e da demanda devem ser iguais, de outro modo, teríamos excesso de capacidade ou de demanda. Se for verdade que a principal restrição sobre o crescimento de longo prazo está no balanço de pagamentos, os mecanismos que levam à convergência da taxa de crescimento da oferta à imposta pelo BP ainda não foram devidamente explorados.

Em termos de suporte empírico, a lei de Thirlwall tem encontrado grande aceitação, o que tem lhe permitido se consolidar na literatura pós-keynesiana de crescimento. A evidência, no entanto, se divide entre trabalhos que apontam para a significância do efeito dos preços e da renda no crescimento de longo prazo e aqueles que apontam apenas para a significância da última. Thilrwall (1979), no artigo em que desenvolveu a lei que leva seu nome, testou sua formulação para o período 19531976 em uma amostra de 18 países. O autor encontra estimativas para a taxa de crescimento compatíveis com a taxa de crescimento efetiva.

Thirlwall e Hussain (1982), sabendo da importância que fluxos financeiros têm em economias em desenvolvimento, estendem o exercício original incorporando os fluxos financeiros para 15 países entre 1951-1969. A conclusão de sua análise indica que o movimento de capitais foi significativo na determinação da taxa de crescimento compatível com o equilíbrio no BP. Ademais, encontra-se que mudanças nos preços relativos foram estatisticamente significativas para alguns países da amostra.

Contrariando esse resultado, Alonso e Garcimartín (1999), utilizando data para um grupo de 10 países membros da OCDE entre 1965-1994, mostram que a lei de Thirlwall se sustenta empiricamente e que os preços relativos não têm papel significativo em termos de crescimento econômico. Os resultados encontrados corroboram a posição keynesiana não havendo evidência significativa de ajuste nos preços.

Romero, Silveira e Jayme Jr. (2011) encontram que o modelo de Thirlwall simples e em sua versão multissetorial explicam com sucesso o crescimento econômico brasileiro nos últimos cinquenta anos. Os autores empregam três métodos distintos de estimação para os anos 1962 a 2007. Gouvea e Lima (2010) testam a lei de Thirlwall multissetorial para uma amostra de 8 países, 4 asiáticos e 4 latinoamericanos entre 1962 e 2006, encontrando que não se pode rejeitar a hipótese de que o crescimento desses países é restringido pelo balanço de pagamentos.

Utilizando amostras maiores, Cimoli; Porcile e Rovira (2010) realizam um exercício econométrico verificando a aplicabilidade da lei de Thirlwall para 29 países, 8 latino-americanos, 15 membros da OCDE e 6 asiáticos. O período analisado compreende os anos de 1961 a 2004. Além do suporte encontrado a favor da formulação de Thirlwall, mostra-se que a evolução das elasticidades das importações 
e exportações no tempo entre os países latino-americanos e asiáticos é capaz de explicar a trajetória divergente de suas rendas per capita.

Por fim, em um esforço bastante ambicioso, Gouvea e Lima (2013) testam a versão multissetorial da lei de Thirlwall para uma amostra de 90 economias entre 1965 e 1999. O poder preditivo do modelo é testado comparando a taxa de crescimento prevista com a taxa de crescimento efetiva. Apesar do crescimento de todos os países não ser restrito pelo balanço de pagamentos, conforme esperado, a "curva de $45^{\circ}$ " não pode ser rejeitada a um nível de significância de $5 \%$, o que dá suporte à lei.

Embora tenha desenvolvido seu modelo de forma independente, Thirlwall (1983) menciona as similaridades entre a sua formulação e a de Prebisch. No entanto, diferentemente da generalização de Thirwall, Prebisch argumentava que as restrições ao crescimento no BP eram impostas apenas para os países mais periféricos e não aos do centro (Boianovsky; Solís, 2014). McCombie (2011) reconhece que os países menos desenvolvidos têm maiores probabilidades de terem seu crescimento restringido pelo balanço de pagamentos, contudo essa condição não é de exclusividade.

\section{Conciliando Prebisch-Singer e Thirlwall}

Como se antecipou na introdução geral, as considerações desta seção versam sobre nossa proposta de aprofundar a relação entre a escola cepalina e póskeynesiana por meio da aproximação dos trabalhos de Prebisch e Thirwall. Conforme argumentado por Cimoli, Porcile e Rivera (2010), os modelos de crescimento com restrição no balanço de pagamentos podem ser usados para capturar importantes elementos tanto da tradição keynesiana quanto estruturalista.

Na literatura keynesiana, Block e Sapsford (2000) e Sarkar (2001) desenvolveram modelos compatíveis com a hipótese Prebisch-Singer, embora independentes da tradição BOPC. Por outro lado, Dutt (2002, 2003) e Ros (2013) estudaram a dinâmica dos termos de troca usando a definição tradicional para a taxa de câmbio. Ambos os autores analisam a possibilidade de uma deterioração contínua dos termos de troca causada por diferenças nas elasticidades de comércio exterior. Um exercício similar é feito por Araújo (2013), partindo de uma abordagem pasinettiana multissetorial.

Nossa proposta, por outro lado, consiste em introduzir a hipótese PrebischSinger por meio de uma definição alternativa da taxa de câmbio. São três as principais vantagens da abordagem desenvolvida: (i) a deterioração dos termos de troca passa a ser caracterizada por quebras estruturais, como sugerido pela evidência empírica; (ii) as quebras estruturais decorrem de diferenças nas estruturas de mercado de bens primários e industriais; (iii) o setor de serviços é introduzido na 
economia. Os modelos teóricos até aqui desenvolvidos são compatíveis com uma deterioração contínua dos termos de troca, o que não é corroborado empiricamente. Ademais, a deterioração decorre de diferenças nas elasticidades de comércio exterior, o que corresponde a um dos mecanismos apontados por Prebisch-Singer. Nosso exercício permite explorar um segundo mecanismo, a saber, diferenças nas estruturas de mercado que são captadas por um componente de mark-up.

Em seu trabalho original, Thirlwall utiliza uma função para a taxa de câmbio real compatível com a PPP de tal forma que, enquanto $(1+\varphi+\beta)$ capta a chamada condição de Marshall-Lerner, êcorresponde à variação na taxa de câmbio real e seria igual a zero no longo prazo. De fato, tanto Thirlwall quanto os autores que o sucedem definem a taxa de câmbio real como:

$$
E=\frac{P_{f} \varepsilon}{P_{d}}
$$

Onde $P_{d}$ corresponde ao nível de preços internos, $P_{f}$ ao nível de preços externos e $\varepsilon$ à taxa de câmbio nominal.

Araújo (2013) argumenta que a PPC não seria a definição mais conveniente para o estudo do efeito da variação dos preços relativos sobre o crescimento. De acordo com Rogoff (1996), mesmo que aceitemos a paridade do poder de compra, ela parece sustentar-se apenas no longuíssimo prazo com uma velocidade de convergência extremamente lenta. Além de verificar-se apenas para períodos muito longos, acima de 50 anos, a relação entre a lei de Kaldor-Verdoorn e a lei de Thirlwall só se sustenta desde que não aceitemos PPP na medida em que uma das pontes entre as duas formulações é estabelecida via preços. Mais ainda e para efeitos deste trabalho, a adoção da paridade do poder de compra não permite captar a tese Prebisch-Singer da deterioração dos termos de troca. Nessa direção, a definição proposta por Rodrik (2008) parece mais apropriada. Seja:

$$
E=\frac{P_{T}}{P_{N}}
$$

em que $E$ corresponde à taxa de câmbio real, $P_{T}$ é dado pelos preços dos bens transacionáveis e $P_{N}$ pelos preços dos bens não transacionáveis. Como mostrado por Rodrik (2008), essa definição é compatível com o efeito Balassa-Samuelson e será empregada na proposta de modelagem apresentada ${ }^{5}$.

Segundo Di Filippo (2009), a teoria estruturalista do valor e da formação de preços se encontra em um ponto intermediário entre a teoria marxista, em que os preços são a expressão social do trabalho inserido em seus produtos, e a abordagem

(5) O efeito Balassa-Samuelson postula que os ganhos de produtividade são maiores no setor tradable do que no non-tradable. Uma predição relacionada a este efeito é que países com maiores taxas de crescimento experimentarão maior apreciação cambial. Como mostraremos adiante, isso não é necessariamente verdade. 
neoclássica, em que os preços são simples manifestação da utilidade marginal. Assume-se, mesmo que implicitamente, que a existência do mercado reflete a posição de poder dos atores sociais em relação às diferentes esferas de cada sociedade (Bielschowsky, 2009; Di Filippo, 2009). Dessa forma, não se nega que os preços reflitam a utilidade e escassez dos recursos, mas que em última análise, a posição de poder, as estratégias e táticas das partes contratantes também determinam os preços.

Bielschowsky (2009) e Di Filippo (2009), em suas respectivas análises sobre o pensamento estruturalista cepalino, mostram que um elemento comum nos trabalhos dentro dessa literatura está na concepção de um sistema multidimensional dinâmico aplicável no estudo dos efeitos de aumentos da produtividade do trabalho gerados nas economias centrais sobre as periféricas. Consideremos, então, uma economia formada por três setores correspondendo à produção de bens primários (setor 1, transacionável), bens industrializados (setor 2, transacionável) e serviços (setor 3, não transacionável). A taxa de câmbio real pode ser representada, então, da seguinte maneira:

$$
E=\frac{P_{T, 1}^{\theta_{1}} P_{T, 2}^{\theta_{2}}}{P_{N}}
$$

Onde $P_{T, 1}$ corresponde aos preços no setor de bens primários, $P_{T, 2}$ aos preços no setor de bens industrializados e $P_{N}$ ao setor de serviços. Por sua vez, $\theta_{1}+\theta_{2}=$ 1 determinam o peso dos setores 1 e 2 na produção total de tradables e são tomados, a princípio, como constantes. Aumentos de produtividade no setor de comercializáveis provocam uma redução de preços que, por sua vez, se refletem em uma taxa de cambio mais apreciada. Já os aumentos de produtividade no setor de serviços têm o efeito contrário, desvalorizando a taxa de câmbio real. A validade do efeito Balassa-Samuelson implica que o aumento da produtividade nos setores tradables seja maior que no non-tradable. A taxa de variação do cambio é dada por:

$$
\hat{e}=\theta_{1} \widehat{p_{T, 1}}+\theta_{2} \widehat{p_{T, 2}}-\widehat{p_{N}}
$$

Seguindo Porcile e Lima (2006), consideremos que os preços são determinados no primeiro setor por um mark-up que capta o poder de mercado das firmas. Os demais setores operam em mercado competitivo. Assim:

$$
\left\{\begin{array}{l}
P_{T, 1}=w q_{T, 1}^{-1} \\
P_{T, 2}=\tau w q_{T, 2}^{-1} \\
P_{N}=w q_{N}^{-1}
\end{array}\right.
$$

O poder de mercado no setor manufatureiro é representado por $\tau>0$, sendo que neste trabalho consideraremos que ele é intrínseco à própria estrutura do mercado em questão, esteja ele operando em concorrência monopolística ou em situação de oligopólio. Observamos que o mark-up deriva da presença de um maior 
poder de barganha por parte dos trabalhadores e da concentração da inovação no setor industrial. Os trabalhadores do setor industrial, ao estarem organizados na forma de sindicatos, estão em melhores condições de reivindicar melhoras salariais como descrito por Prebisch. Por outro lado, como apresentado por Singer, quando uma empresa inova, ela ganha o direito de cobrar um mark-up sobre os preços. Por fim, $w$ corresponde ao salário nominal e $q$ à produtividade do trabalho.

Logaritmando as equações (4.5a), (4.5b) e (4.5c) e derivando no tempo:

$$
\left\{\begin{array}{l}
\widehat{p_{T, 1}}=\widehat{w}-\widehat{q_{T, 1}} \\
\widehat{p_{T, 2}}=\hat{\tau}+\widehat{w}-\widehat{q_{T, 2}} \\
\widehat{p_{N}}=\widehat{w}-\widehat{q_{N}}
\end{array}\right.
$$

Obtemos, dessa forma, as funções que determinam a taxa de variação dos preços na economia. Aumentos de produtividade levam a reduções dos níveis de preços enquanto que aumentos dos salários têm o efeito contrário. No setor industrial, um aumento da taxa de inovação ou do poder de barganha dos trabalhadores provoca um aumento do $\hat{\tau}$ resultando em maiores preços. A taxa de variação do mark-up pode ainda ser modelada por meio de uma função escalão unitário em que:

$$
\hat{\tau}=\left\{\begin{array}{c}
h \widehat{q_{T, 2}}, \text { se há inovação ou aumento do poder de barganha } \\
0 \text {, caso contrário }
\end{array}\right.
$$

Seguindo Ferrari, Freitas e Barbosa Filho (2013), reconstruímos o sistema original do modelo de Thirlwall para nossa economia com três setores:

$$
\left\{\begin{array}{l}
X_{T, i}=(1 / E)^{\varphi_{T, i} Z^{\Phi_{T, i}}} M_{T, i}=(E)^{\beta_{T, i} Y^{\pi_{T, i}}(4.7 \mathrm{~b})} \\
\sum_{i=1}^{2} X_{T, i}=E \sum_{i=1}^{2} M_{T, i}
\end{array}\right.
$$

em que a função de exportações, importações e a condição de equilíbrio foram desagregadas nos dois setores comercializáveis de modo que $X=X_{T, 1}+X_{T, 2}$ e $M=$ $M_{T, 1}+M_{T, 2} \operatorname{comi}=1,2$.

Utilizando o mesmo ferramental empregado até aqui, obtemos que:

$$
\left\{\begin{array}{l}
\hat{x}_{T, i}=-\varphi_{T, i} \hat{e}+\Phi_{T, i} \hat{z} \\
\hat{m}_{T, i}=\beta_{T, i} \hat{e}+\pi_{T, i} \hat{y} \\
\alpha_{1} \hat{x}_{T, 1}+\alpha_{2} \hat{x}_{T, 2}=\hat{e}+\gamma_{1} \widehat{m}_{T, 1}+\gamma_{2} \widehat{m}_{T, 2}
\end{array}\right.
$$

onde os parâmetros $\alpha$ e $\gamma$ correspondem ao peso de cada setor na pauta de exportações e importações, respectivamente $\left(\alpha_{1}+\alpha_{2}=1\right.$ e $\left.\gamma_{1}+\gamma_{2}=1\right)$.

Substituindo (4.8a) e (4.8b) em (4.8c) e isolando $\hat{y}$, obtemos a taxa de crescimento compatível com o equilíbrio no balanço de pagamentos: 
$\hat{y}=-\left(\frac{1+\sum_{i=1}^{2} \alpha_{i} \varphi_{T, i}+\sum_{i=1}^{2} \gamma_{i} \beta_{T, i}}{\sum_{i=1}^{2} \gamma_{i} \pi_{T, i}}\right) \hat{e}+\left(\frac{\sum_{i=1}^{2} \alpha_{i} \Phi_{T, i}}{\sum_{i=1}^{2} \gamma_{i} \pi_{T, i}}\right) \hat{z}$

Procurando conciliar a visão cepalina de poder com as proposições feitas por Setterfield (2011) e Araújo (2013), substituímos a definição de câmbio real adotada por Thirlwall (1979) pela adotada por Rodrik (2008) e previamente modificada (ver equações 4.3 e 4.4). Dessa forma, temos que:

$$
\begin{gathered}
\hat{y}=\frac{-\left(1+\sum_{i=1}^{2} \alpha_{i} \varphi_{T, i}+\sum_{i=1}^{2} \gamma_{i} \beta_{T, i}\right)\left(\theta_{1} \widehat{p_{T, 1}}+\theta_{2} \widehat{p_{T, 2}}-\widehat{p_{N}}\right)}{\sum_{i=1}^{2} \gamma_{i} \pi_{T, i}} \\
+\left(\frac{\sum_{i=1}^{2} \alpha_{i} \Phi_{T, i}}{\sum_{i=1}^{2} \gamma_{i} \pi_{T, i}}\right) \hat{z}
\end{gathered}
$$

No entanto, sabemos do sistema (4.6) o comportamento dos preços em cada um dos setores dessa economia. Fazendo as devidas substituições e após algumas manipulações algébricas:

$$
\begin{gathered}
\hat{y}=\frac{-\left(1+\sum_{i=1}^{2} \alpha_{i} \varphi_{T, i}+\sum_{i=1}^{2} \gamma_{i} \beta_{T, i}\right)\left[-\theta_{1} \widehat{q_{T, 1}}+\theta_{2}\left(\hat{\tau}-\widehat{q_{T, 2}}\right)+\widehat{q_{N}}\right]}{\sum_{i=1}^{2} \gamma_{i} \pi_{T, i}} \\
+\left(\frac{\sum_{i=1}^{2} \alpha_{i} \Phi_{T, i}}{\sum_{i=1}^{2} \gamma_{i} \pi_{T, i}}\right) \hat{z}
\end{gathered}
$$

Obtemos, dessa forma, a taxa de crescimento que equilibra o BP decomposta no efeito renda - lei de Thirlwall - e efeito preço - compatível com a hipótese Prebisch-Singer.Chamamos essa expressão de Regra Prebisch-Thirlwall. Semelhantemente ao modelo original, a taxa de crescimento é diretamente proporcional à taxa de crescimento da renda externa e à razão entre as elasticidades das exportações e importações. Desse modo, quanto maior o crescimento do produto internacional, maior será o crescimento potencial doméstico. Mais ainda, países especializados na produção de bens industrializados apresentarão maior crescimento que o resto do mundo devido à maior elasticidade-renda de suas exportações em detrimento das importações. Por outro lado, países primário-exportadores tenderão a crescer menos que o resto do mundo, já que a elasticidade de suas exportações é inferior à das importações.

Tratando-se de uma economia com 2 setores transacionáveis, o modelo não exclui a possibilidade de mudança estrutural. De fato, temos da mesma forma que em (2.1):

$$
\left\{\begin{array}{l}
\bar{\Phi}=\sum_{1}^{2} \alpha_{i} \Phi_{T, i} \\
\bar{\pi}=\sum_{1}^{2} \gamma_{i} \pi_{T, i}
\end{array}\right.
$$


Onde $\bar{\Phi}$ e $\bar{\pi}$ correspondem às elasticidades médias das exportações e importações, respectivamente. Diferenciando ambas as equações em relação ao tempo:

$$
\left\{\begin{array}{l}
\dot{\bar{\Phi}}=\sum_{1}^{2} \dot{\alpha}_{l} \Phi_{T, i}+\sum_{1}^{2} \alpha_{i} \dot{\Phi}_{T, l} \\
\dot{\bar{\pi}}=\sum_{1}^{2} \dot{\gamma}_{l} \pi_{T, i}+\sum_{1}^{2} \gamma_{i} \pi_{T, l}
\end{array}\right.
$$

O progresso técnico é capaz de modificar as elasticidades renda, tanto da pauta exportadora quanto importadora, processo captado pelo segundo componente do sistema acima. Por sua vez, a transferência de trabalhadores de setores com menor elasticidade-renda para segmentos de maior elasticidade também contribui positivamente para o aumento do crescimento potencial, como mostrado pelo primeiro componente. Mesmo em um contexto externo adverso, modificações na proporção de cada setor na economia permitem alcançar maiores taxas de crescimento.

Ao não assumir PPP e tomando a condição de Marshall-Lerner como válida, nossa formulação é compatível com a ampla evidência apresentada a favor da hipótese Prebisch-Singer de deterioração dos termos de troca. Os ganhos de produtividade decorrentes do processo de crescimento econômico levam naturalmente a uma apreciação da taxa de câmbio, via efeito Balassa-Samuelson, que reduz a taxa de crescimento compatível com o equilíbrio no balanço de pagamentos. No entanto, o progresso técnico e a estrutura do mercado no setor industrial conseguem simultaneamente reduzir a intensidade da valorização por meio do mark-up. Como as atividades de P\&D concentram-se no setor 2, países especializados na produção do setor 1 apresentarão uma restrição ao crescimento maior decorrente da valorização da taxa de câmbio real. Perceba, no entanto, que ao modelar $\hat{\tau}$ como uma função escalar unitário, sua variação não ocorre de forma contínua.

A título de exemplificação, consideremos os casos extremos de uma economia central e outra periférica, plenamente especializados na produção de bens industrializados e primários, respectivamente. No primeiro caso, o setor 2 é responsável por toda a produção dos bens transacionáveis $\left(\theta_{2}=1\right)$. Assim, a taxa de crescimento compatível com a restrição no balanço de pagamentos respeitará a seguinte igualdade:

$\hat{y}=\frac{-\left(1+\varphi_{T, 2}+\beta_{T, 1}\right)\left[\left(\hat{\imath}-\widehat{q_{T, 2}}\right)+\widehat{q_{N}}\right]}{\pi_{T, 1}}+\left(\frac{\Phi_{T, 2}}{\pi_{T, 1}}\right) \hat{z}$

O progresso técnico e/ou variações no poder de barganha dos trabalhadores, que por hipótese se concentram no setor industrial, permitem contrabalançar os efeitos da valorização da taxa de câmbio real por meio de uma variação na taxa de 
mark-up. Embora o efeito Balassa-Samuelson prevaleça no longo prazo, ele será menos intenso.

No caso de uma economia totalmente especializada na produção de commodities primárias $\left(\theta_{1}=1\right)$, a taxa de crescimento no longo prazo será dada por:

$\hat{y}=\frac{-\left(1+\varphi_{T, 1}+\beta_{T, 2}\right)\left[-\widehat{q_{T, 1}}+\widehat{q_{N}}\right]}{\pi_{T, 2}}+\left(\frac{\Phi_{T, 1}}{\pi_{T, 2}}\right) \hat{z}$

À medida que são obtidos ganhos de produtividade tanto no setor de comercializáveis quanto no de não comercializáveis, observa-se uma valorização da taxa de câmbio real que deteriora o desempenho do balanço de pagamentos. Como o mercado de bens primários opera em competição perfeita, podemos considerar que há uma deterioração dos termos de troca dos produtos primários em relação aos produtos industrializados, determinada pela diferença nas estruturas setoriais de mercado.

Ganhos de produtividade no setor tradable levam, via preços, à redução da taxa de crescimento potencial da economia em ambos os casos. A existência de estruturas de mercado tecnologicamente oligopolizadas nos países do centro reduz esse efeito por meio do mark-up que a própria inovação permite às firmas possuir. Como o mercado de commodities primárias se aproxima de uma estrutura competitiva, os ganhos de produtividade se traduzem necessariamente em uma redução de preços, caracterizando a deterioração descrita por Prebisch.

A evidência empírica existente em favor da hipótese Prebisch-Singer sugere que a deterioração não ocorreu de forma contínua, sendo marcada por quebras estruturais. O modelo desenvolvido neste trabalho também é compatível com essa observação. De fato, a deterioração dos termos de troca só seria continua se a taxa de mark-up crescesse também de forma contínua, o que claramente não é possível. No entanto, o progresso técnico, do qual deriva o poder de mercado das firmas, é descontinuo e, até certo ponto, as grandes inovações são imprevisíveis.

No momento em que surge uma grande inovação ou há um choque nas condições de barganha a favor dos trabalhadores, tem-se uma grande elevação de $\hat{\tau}$ que provoca uma brusca deterioração dos termos de troca dos produtos primários em relação aos manufaturados, caracterizando as quebras estruturais observadas. Seguese então um período de relativa estabilidade dos preços de ambos os setores. Ocampo e Parra (2003), Zanias (2005) e Ocampo e Parra (2010) identificam duas grandes quebras estruturais durante o século XX, sendo a primeira por volta de 1920 e a segunda durante a década de 1980, como pode ser visto no Gráfico 1. À luz do modelo apresentado houve efetivamente dois choques sobre a taxa de mark-up. 
Gráfico 1

Evolução dos termos de troca entre produtos primários e industrializados entre 1900 e 2003

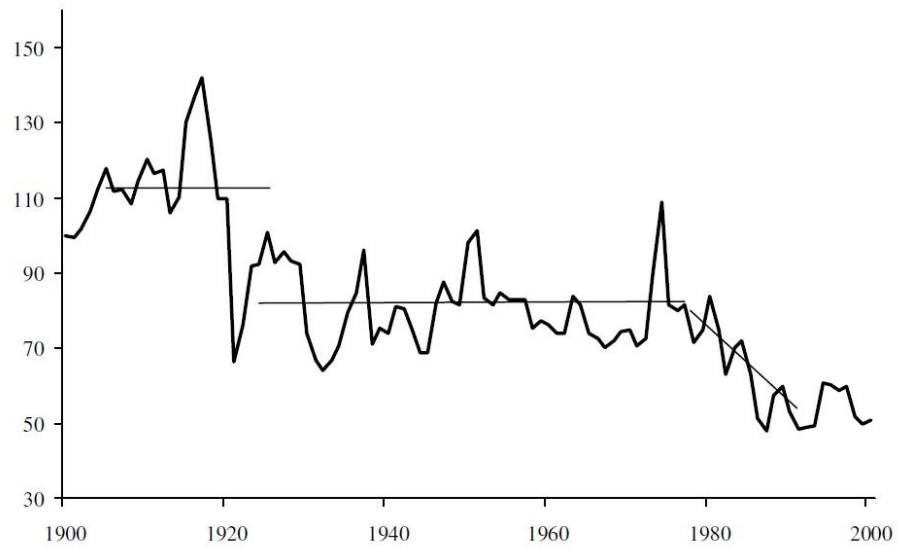

Fonte: Ocampo e Parra (2003).

As duas principais variáveis por trás do crescimento de longo prazo continuam sendo a taxa de crescimento internacional e a razão entre a elasticidaderenda das exportações e importações. Elas são os determinantes de fato do crescimento de longo prazo e se sobrepõem ao efeito dos preços. A maior parte da evidência empírica mostra que o efeito preço não é estatisticamente significativo. Isso não invalida os resultados apresentados já que a especialização completa requerida pelas equações 3.14(a) e 3.14(b) corresponde a um exemplo didático. A abordagem apresentada, no entanto, acrescenta um novo elemento nesse referencial ao permitir captar o efeito dos preços sobre o crescimento a partir da hipótese Prebisch-Singer de deterioração dos termos de troca. Chamamos a expressão final denotada pela equação (4.11) de Regra Prebisch-Thirlwall.

\section{Causação cumulativa e a regra Prebisch-Thirlwall}

A literatura pós-keynesiana desenvolveu dois diferentes modelos de crescimento de longo prazo para economias abertas, a saber, os modelos de causação cumulativa originalmente concebidos por Nicholas Kaldor (1966) e os modelos de restrição no balanço de pagamentos já apresentados na terceira seção. Embora ambas as abordagens divirjam significativamente em algumas de suas hipóteses (Blecker, 2009), importantes resultados podem ser extraídos de sua combinação ${ }^{6}$.

As raízes do conceito de causação cumulativa estão em Myrdal (1960) ao argumentar que os problemas sociais envolvem um complexo processo de mudanças interdependentes circulares e acumulativas. Seguindo essa tradição, os modelos

(6) O modelo de Dixon-Thirlwall corresponde nesse referencial a uma formalização da visão kaldoriana aplicada a um contexto de economia regional. 
kaldorianos são, de maneira geral, formados por um sistema de duas equações em que os componentes de demanda agregada determinam a taxa de crescimento do produto, esta determina a taxa de crescimento da produtividade que, por sua vez, sustenta a expansão da demanda agregada e, consequentemente, retroalimenta o sistema.

Voltando à equação (4.11) e reescrevendo-a em função das elasticidades médias definidas em (4.12a) e (4.12b), encontramos:

$\hat{y}=\frac{-\left(1+\sum_{i=1}^{2} \alpha_{i} \varphi_{T, i}+\sum_{i=1}^{2} \gamma_{i} \beta_{T, i}\right)\left(\theta_{2} \hat{\imath}-\widehat{q_{T}}+\widehat{q_{N}}\right)}{\overline{\pi_{T}}}+\left(\frac{\overline{\Phi_{T}}}{\overline{\pi_{T}}}\right) \hat{z}$

em que $\widehat{q_{T}}=\theta_{1} \widehat{q_{T, 1}}+\theta_{2} \widehat{q_{T, 2}}$. Sendo válida a condição de Marshall-Lerner $-\left(1+\sum_{i=1}^{2} \alpha_{i} \varphi_{T, i}+\sum_{i=1}^{2} \gamma_{i} \beta_{T, i}\right)>0$.

Como sustentado por Araújo (2013) e Romero, Silveira e Jayme Jr. (2011), as elasticidades-renda são determinadas pelo grau de intensidade tecnológica da produção nacional. Assim, setores tecnologicamente líderes e de alto valor agregado apresentariam uma maior elasticidade-renda da demanda. Seguindo, então, Setterfield (2011), consideremos as elasticidades médias como sendo função da taxa de crescimento da produtividade do segmento de tradables, de modo que:

$$
\frac{\overline{\Phi_{T}}}{\overline{\pi_{T}}}=k \widehat{q_{T}}
$$

em que $k>0$ é um parâmetro linear que capta a sensibilidade das elasticidades à taxa de variação da produtividade. Países especializados na produção de bens industriais de elevada intensidade tecnológica tendem a apresentar um $k$ elevado, contrastado com países tecnologicamente atrasados. O padrão de especialização no comércio mundial determina a forma como os frutos do progresso técnico serão divididos entre países.

A taxa de variação do mark-up foi modelada anteriormente por meio de uma função escalão unitário linearmente dependente da taxa de crescimento da produtividade do setor industrial. Para efeito de simplificação ${ }^{7}$, nesta representação ela dependerá da taxa de crescimento da produtividade dos tradables. Estando os ganhos de produtividade concentrados nesse segmento, escrevemos ainda a taxa de variação da produtividade do setor non-tradable como função linear da taxa de variação da produtividade no segmento de comercializáveis. Assim:

$$
\begin{aligned}
& \hat{\tau}=h \widehat{q_{T}} \\
& \widehat{q_{N}}=l \widehat{q_{T}}
\end{aligned}
$$

(7) A taxa de variação do mark-up não pode ser uma função contínua crescente da produtividade, de outro modo teríamos mark-ups tendendo a infinito. A representação empregada é utilizada apenas para fins de simplificação da modelagem. 
Com $h>0$ correspondendo à sensibilidade do mark-up a variações na produtividade e $0<l<1$ representando a proporção da inovação do setor de não comercializáveis em relação ao de comercializáveis.

Substituindo então o sistema formado pelas equações (5.2) em (5.1) e após algumas manipulações algébricas, obtemos nossa taxa de crescimento compatível com o equilíbrio no balanço de pagamentos. Juntando esse resultado com a lei de Kaldor-Verdoorn temos nosso sistema de causação cumulativa:

$$
\left\{\begin{array}{l}
\hat{y}=\Omega_{1} \widehat{q_{T}}+\Omega_{2}{\widehat{q_{T}}}^{2} \\
\widehat{q_{T}}=\zeta_{0}+\zeta_{1} \hat{y}
\end{array}\right.
$$

em que $\Omega_{1}=k \hat{z}$ corresponde ao efeito renda de variações na produtividade, $\Omega_{2}=$ $-\frac{\left(1+\sum_{i=1}^{2} \alpha_{i} \varphi_{T, i}+\sum_{i=1}^{2} \gamma_{i} \beta_{T, i}\right)\left(\theta_{2} h+l-1\right)}{\bar{\Phi}_{T}}<0$ corresponde ao efeito preço, $\zeta_{0}>0$ é uma constante e $\zeta_{1}>0$ capta a sensibilidade da taxa de crescimento da produtividade em relação à taxa de crescimento do produto. A equação (5.3a) corresponde ao regime do balanço de pagamentos enquanto (5.3b), ao regime de produtividade. O Gráfico 2(a) nos permite visualizar o comportamento de ambas as expressões:

\section{Gráfico 2}

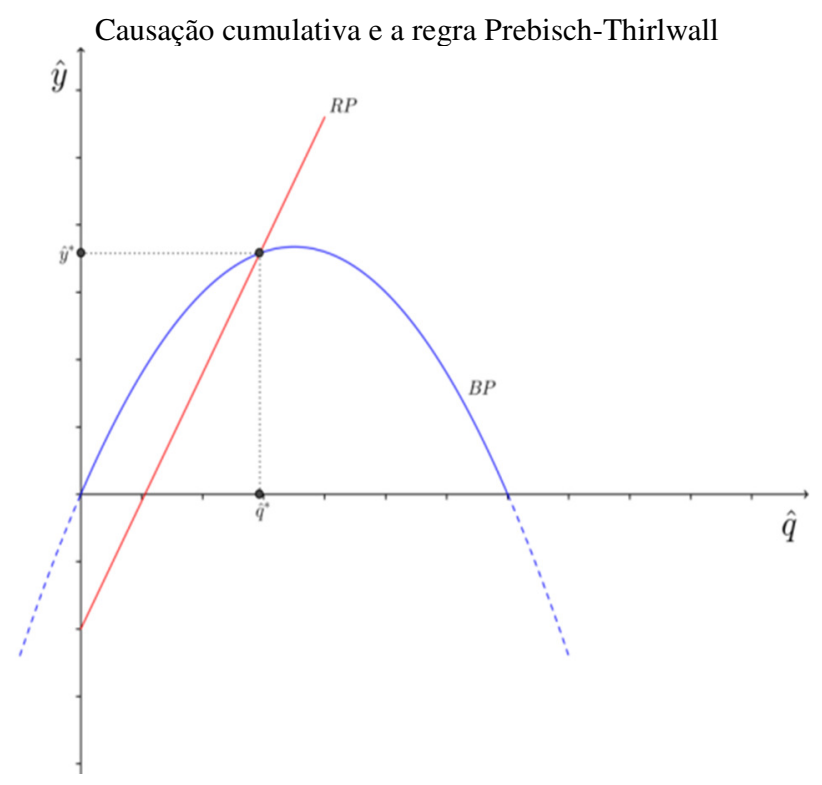

(a) 


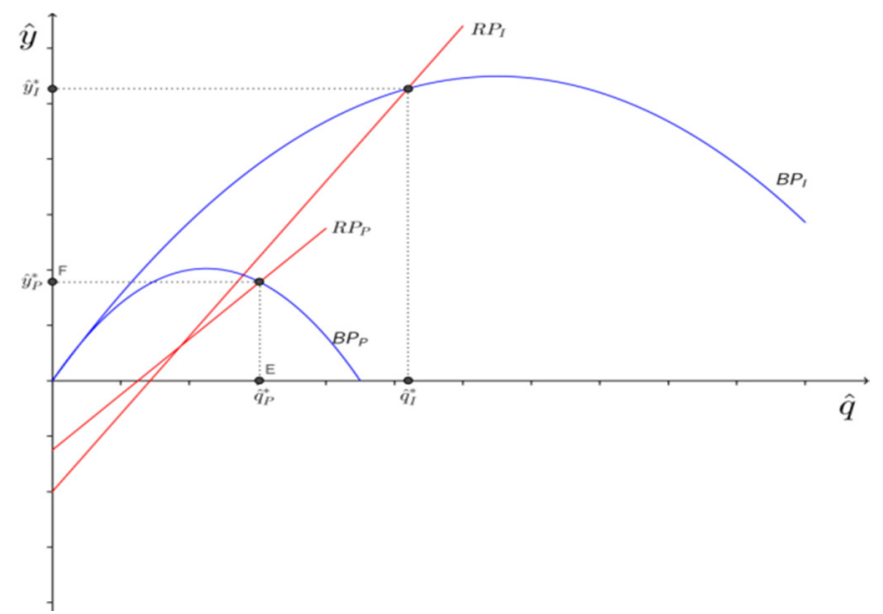

(b)

Elaborado pelos autores.

Alguns insights importantes podem ser extraídos da modelagem apresentada. O primeiro deles sugere que a taxa de crescimento do produto depende quadraticamente da taxa de crescimento da produtividade. A curva BP é formada por todas as combinações de $\widehat{q_{T}}$ e $\hat{y}$ que mantêm equilibrado o balanço de pagamentos.Economias cujo equilíbrio se encontra antes do vértice da parábola do regime BP apresentam uma relação positiva entre as variáveis endógenas de modo que choques de produtividade que deslocam RP, elevam a taxa de crescimento que equilibra o BP. Por outro lado, economias cujo equilíbrio se encontra depois do vértice de BP apresentam uma relação negativa entre as variáveis endógenas. Assim, choques positivos de produtividade têm efeito negativo sobre a taxa de crescimento, já que o efeito preço começa a se sobrepor ao efeito renda.

A taxa de crescimento da produtividade, por sua vez, depende diretamente da taxa de crescimento do produto por meio do mecanismo proposto por KaldorVerdoorn. Dessa forma, a restrição externa condiciona as variações da produtividade de uma economia. Podemos argumentar que países com elevado $k$ e $\zeta_{1}$ são os mais propensos a entrar em círculos virtuosos de crescimento. De modo contrário, a combinação de um baixo $k$ e $\zeta_{1}$ implica uma maior propensão a entrar em círculos viciosos de crescimento.

Blecker (2009) e Amitrano (2013) desenvolvem modelos em que se procura alcançar objetivos semelhantes aos apresentados nesta seção. Empregando a definição convencional para a taxa de câmbio, o autor encontra uma curva BP de inclinação positiva de modo que aumentos na produtividade do trabalho levariam necessariamente a aumentos na taxa de crescimento da economia. A diferença crucial entre ambas as abordagens está na definição empregada para a taxa de 
câmbio. Cremos que o amplo suporte empírico encontrado a favor do efeito BalassaSamuelson e da hipótese Prebisch-Singer sustentam nossa proposição.

Do mesmo modo que nos passos anteriores, as duas principais variáveis por trás do crescimento de longo prazo continuam sendo a taxa de crescimento internacional e a razão entre a elasticidade-renda das exportações e importações. Elas são os determinantes de fato do crescimento de longo prazo, o que significa que o efeito renda se sobrepõe amplamente ao efeito preço. O modelo permanece compatível com a mudança estrutural na medida em que tanto o progresso técnico como a transferência de trabalhadores de setores com menor elasticidade-renda para segmentos de maior elasticidade são capazes de alterar a elasticidade média da pauta de comercio exterior e, por conseguinte, modificar a taxa de crescimento. A abordagem apresentada ainda é compatível com a hipótese Prebisch-Singer de deterioração dos termos de troca dos produtos primários em relação aos manufaturados.

A título de exemplificação, consideramos os casos extremos de uma economia central e outra periférica, plenamente especializados na produção de bens industrializados e primários, respectivamente. No primeiro deles, observa-se uma combinação de $\Omega_{1}$ e $\zeta_{1}$ elevados e $\Omega_{2}$ baixo. O $\Omega_{1}$ elevado ocorre porque os países centrais são exportadores de produtos tecnologicamente avançados com elevada elasticidade-renda e importam insumos primários de menor elasticidade-renda. $\mathrm{O} \zeta_{1}$ elevado também é garantido pela liderança tecnológica do centro que lhes confere sistemas educacionais e de pesquisa mais avançados além de maiores mercados consumidores. Por fim, o $\Omega_{2}$ baixo decorre não apenas da elevada elasticidade renda das exportações (ver denominador da expressão), como também da presença de poder de mercado das firmas no setor industrial.

O país da periferia por sua vez apresenta uma combinação de $\Omega_{1}$ e $\zeta_{1}$ baixos e $\Omega_{2}$ alto.O $\Omega_{1}$ baixo ocorre porque trata-se de uma economia primário-exportadora, importadora de produtos industrializados com elevada elasticidade renda e cujas exportações apresentam baixa elasticidade renda. $\mathrm{O} \zeta_{1}$ reduzido também decorre de seu atraso tecnológico, o que lhes confere sistemas educacionais e de pesquisa mais frágeis além de menores mercados consumidores. Por fim, o $\Omega_{2}$ mais alto decorre não apenas da baixa elasticidade renda das exportações (ver denominador da expressão) como da ausência de poder de mercado das firmas no setor industrial.

A comparação das curvas do regime de produtividade e do regime do BP entre o país do centro e da periferia nos permite notar que a taxa de crescimento que equilibra o balanço de pagamentos é maior no primeiro do que no último, o que pode ser observado no Gráfico $2(\mathrm{~b})$. As curvas $\mathrm{RP}_{\mathrm{I}}$ e $\mathrm{BP}_{\mathrm{I}}$ correspondem aos regimes de produtividade e do balanço de pagamentos, respectivamente, no país central. Analogamente, as curvas $\mathrm{RP}_{\mathrm{P}}$ e $\mathrm{BP}_{\mathrm{P}}$ correspondem aos regimes de produtividade $\mathrm{e}$ 
do balanço de pagamentos, respectivamente, no país periférico. $\mathrm{O}$ crescimento no centro será maior via preços pela presença do fator de mark-up e principalmente pelas diferenças nas elasticidades-renda, cujo efeito é captado pelo parâmetro $\Omega_{1}(k)$. Como explicado anteriormente, nos países industrializados, $k$ é maior do que nos países primário-exportadores.

Como descrito por Prebisch (1959), choques positivos de produtividade em países periféricos não se refletem em aumentos na taxa de crescimento da economia e apenas geram a transferência dos frutos do progresso técnico ao centro. De fato, para um deslocamento à direita da curva $\mathrm{RP}_{\mathrm{p}}$, temos uma redução da taxa de crescimento do produto. Em termos de política econômica, seria aconselhável aumentar a inclinação de $\mathrm{RP}_{\mathrm{p}}$ e deslocar a curva $\mathrm{BP}$ para cima, aliviando dessa forma a restrição externa.

Caso um país em desenvolvimento promova seu setor industrial com um enfoque exportador, ele não apenas é capaz de elevar sua taxa de crescimento, como também o aumento da taxa de crescimento de sua produtividade. Isso pode ser visto por meio de deslocamentos da curva BP na vertical e explica as diferenças no padrão de crescimento entre o sudeste Asiático e a América Latina. Enquanto os primeiros se centraram na elevação das elasticidades-renda e fizeram da defesa dos preços um esforço secundário, os segundos dedicaram uma atenção maior à defesa dos preços via protecionismo alfandegário. Como o efeito renda prevalece sobre o preço, conseguimos explicar o menor crescimento do produto e da produtividade nesta última ${ }^{8}$. Situações intermediárias podem ser descritas a partir de combinações distintas dos parâmetros $\Omega_{1}, \zeta_{1}$ e $\Omega_{2}$ e da mesma forma serem utilizadas para explicar também o comportamento de algumas exceções à dinâmica clássica centro-periferia descrita pelos autores cepalinos.

\section{Conclusão}

O trabalho revisou o modelo básico de crescimento com restrição no balanço de pagamentos e seus principais desdobramentos, sugerindo que a Lei de Thirlwall pode ser entendida como uma formalização matemática do pensamento cepalino derivado da regra de Prebisch. Obtivemos ainda a taxa de crescimento de equilíbrio do BP decomposta no efeito renda - lei de Thirlwall - e efeito preço - hipótese Prebisch-Singer. Chamamos essa expressão final de Regra Prebisch-Thirlwall.

Supondo uma economia formada por três setores - produção de bens industrializados, bens primários e serviços - a taxa de crescimento econômico de longo prazo foi derivada a partir de uma definição distinta para a taxa de câmbio real, incompatível com PPP e compatível com o efeito Balassa-Samuelson. A título

(8) Para uma revisão das diferenças do padrão de crescimento asiático e o latino-americano à luz do desempenho do balanço de pagamentos, ver Cimoli; Porcile e Rovira (2010). 
de exemplificação consideramos os casos extremos de uma economia central e outra periférica, plenamente especializados na produção de bens industrializados e primários, respectivamente.

O progresso técnico, que por hipótese se concentra no setor industrial, e eventuais choques no poder de barganha dos trabalhadores permitem contrabalançar os efeitos da valorização da taxa de câmbio real por meio do poder de mercado que a inovação confere à firma inovadora. Embora o efeito Balassa-Samuelson prevaleça no longo prazo, ele será menos intenso na economia central do que na periférica.

Como o mercado de bens primários opera em competição perfeita, podemos considerar que há uma deterioração dos termos de troca dos produtos primários em relação aos produtos industrializados, determinada pela diferença nas estruturas setoriais de mercado. Essa deterioração repercute negativamente sobre a taxa de crescimento compatível com o equilíbrio no balanço de pagamentos das economias primário-exportadoras, reforçando sua posição periférica.

Nosso modelo ainda é compatível com as conclusões da lei de Thirlwall original e sua versão multissetorial. De fato, as duas principais variáveis por trás do crescimento de longo prazo continuam sendo a taxa de crescimento internacional e a razão entre a elasticidade-renda das exportações e importações. Dessa forma, economias industrializadas cresceriam potencialmente acima do restante do mundo na medida em que a elasticidade de suas exportações é superior à de suas importações. Por outro lado espera-se o efeito contrário em economias primárioexportadoras. Em termos de mudança estrutural, a transferência de trabalhadores do setor primário para o industrial contribui positivamente para o crescimento via mudança na composição das elasticidades do comércio exterior.

A abordagem apresentada acrescenta um terceiro elemento nesse referencial ao permitir captar o efeito dos preços sobre o crescimento a partir da hipótese Prebisch-Singer de deterioração dos termos de troca dos produtos primários em relação aos manufaturados. A evidência empírica sugere que essa deterioração não ocorre de forma contínua e sim escalonada por meio de quebras estruturais. $\mathrm{O}$ modelo construído é compatível com essa observação. A deterioração dos termos de troca só seria contínua se a taxa de mark-up crescesse também de forma contínua, no entanto, o progresso técnico, do qual deriva o poder de mercado das firmas, e alterações no padrão do conflito distributivo são descontínuas. No momento em que surge uma grande inovação, tem-se uma grande elevação de $\hat{\tau}$ que provoca uma brusca deterioração dos termos de troca, caracterizando as observadas quebras estruturais. Segue-se, então, um período de relativa estabilidade dos preços entre ambos os setores.

A principal limitação do exercício desenvolvido está no fato de o modelo apenas representar a restrição do balanço de pagamentos sobre o crescimento 
econômico. O trabalho introduz a dinâmica dos preços sem modelar apropriadamente a interação entre esses setores na estrutura produtiva. Estudar a relação entre setores é agenda para pesquisa futura e permitirá aumentar o grau de proximidade do modelo com o mundo real.

Chamamos a atenção ainda para o fato da maior parte da evidência empírica mostrar que o efeito preço não é estatisticamente significativo. Isso não invalida os resultados apresentados, já que consideramos que a deterioração só apareceria visivelmente nos casos extremos derivados apenas como exemplo didático. Desse modo, a lei de Thirlwall, que corresponde ao efeito renda da regra PrebischThirlwall, é o principal elemento de fato que explica a taxa de crescimento de longo prazo.

Apresentamos ainda uma proposta de junção entre o modelo com restrição no balanço de pagamentos e a tradição pós-keynesiana de causação cumulativa. Encontra-se que a taxa de crescimento do produto depende de forma quadrática da taxa de crescimento da produtividade. A taxa de crescimento da produtividade, por sua vez, depende diretamente da taxa de crescimento do produto por meio do mecanismo proposto por Kaldor-Verdoorn. Em termos de política econômica, caso um país em desenvolvimento promova seu setor industrial com um enfoque exportador, ele não apenas é capaz de elevar sua taxa de crescimento, como também o aumento da taxa de crescimento de sua produtividade. Nossas conclusões reforçam as colocações originalmente feitas pelos autores cepalinos.

\section{Referências bibliográficas}

ALLEYNE, D.; FRANCIS, A. A. Balance of payments-constrained growth in developing countries: a theoretical perspective. Metroeconomica, v. 59, n. 2, p. 189202, 2008.

ALONSO, J. A.; GARCIMARTÍN, C. A new approach to balance-of-payments constraint: some empirical evidence. Journal of Post Keynesian Economics, v. 21, n. 2, p. 259-281, 1999.

AMITRANO, C. Regime de crescimento, restrição externa e financeirização: uma proposta de conciliação. Economia e Sociedade, Campinas, v. 22, n. 2, 2013.

ARAÚJO, R. Cumulative causation in a structural economic dynamic approach to economic growth. Structural Change and Economic Dynamics, v. 24, p. 130-140, 2013.

Assessing the dynamics of terms-of-trade in a model of cumulative causation and structural change. Germany: University Library of Munich, 2013. (MPRA Paper, n. 46049). 
ARAÚJO, R.; LIMA, G. T. A structural economic dynamics approach to balanceof-payments-constrained growth. Cambridge Journal of Economics, v. 31, p. 755774, 2007.

AREZKI, R.; HADRI, K.; LOUNGANI, P.; RAO, Y. Testing the Prebisch-Singer Hypothesis since 1650: evidence from panel techniques that allow for multiple breaks" IMF Working Paper, n. 180, p. 1-35, 2013.

BARBOSA-FILHO. The balance-of-payments constraint: from balanced trade to sustainable debt. BNL Quarterly Review, n. 219, 2001.

BIELSCHOWSKY, R. Sesenta años de la Cepal: estructuralismo y neoestructuralismo. Revista Cepal, n. 97, p. 173-194, 2009.

BLECKER, R. A. Long-run growth in open economies: export-led cumulative causation or a balance-of-payments constraint? American University Working Papers, n. 23, p. 1-36, 2009.

BLOCK, H.; SAPSFORD, D. Whither the terms of trade? An elaboration of the Prebisch-Singer Hypothesis. Cambridge Journal of Economics, v. 24, p. 461-481, 2000.

BOIANOVSKY, M. A view from the tropics: Celso Furtado and the theory of economic development in the 1950s. History of Political Economy, v. 42, p. 221$266,2010$.

; SOLÍS, R. The origins and development of the Latin American structuralist approach to the balance of payments. Review of Political Economy, 2014.

BUNZEL, H.; VOGELSANG, T. Powerful trend function tests that are robust to strong serial correlation with an application to the Prebisch-Singer hypothesis. Journal of Business \& Economic Statistics, v. 23, n. 4, 2005.

CIMOLI, M.; PORCILE, G. Technology, structural change and BOP-constrained growth: a structuralist toolbox. Cambridge Journal of Economics, p. 1-23, 2013.

; PORCILE, G.; ROVIRA, S. Structural change and the BOP-constraint: why did Latin America fail to converge? Cambridge Journal of Economics, v. 34, p. 389-411, 2010.

DI FILIPPO, A. Latin American structuralism and economic theory. Revista de la Cepal, n. 98, p.175-196, 2009.

DUTT, A. Thirlwall's law and uneven development. Journal of Post Keynesian Economics, v. 24, n. 3, p. 367-390, 2002. 
DUTT, A. Income elasticities of imports, North-South trade and uneven development. In: ; ROS, J. Development economics and structuralist macroeconomics. Cheltenham, UK and Northampton, MA, USA: Edward Elgar, 2003.

FERRARI, M. A. R.; FREITAS, F. N. P.; BARBOSA FILHO, N. A taxa de câmbio real e a restrição externa: uma proposta de releitura com elasticidades endógenas. Revista de Economia Política, v. 33, n. 1, p. 60-81, 2013.

FURTADO, C. (1961). Desenvolvimento e subdesenvolvimento. Rio de Janeiro: Contraponto Editora, 2009.

GOUVEA, R. R.; LIMA, G. Structural change, balance-of-payments constraint, and economic growth: evidence from the multisectoral Thirlwall's law. Journal of Post Keynesian Economics, v. 33, n. 1, p. 169-204, 2010.

. Balance of payments constrained growth in a multisectoral

framework: a panel data investigation. Journal of Economic Studies, v. 40, n. 2, p. 240-254, 2013.

GRILLI, E. R.; YANG, M. C. Primary commodity prices, manufactured goods prices, and the terms of trade of developing countries: what the long run shows. The World Bank Economic Review, v. 2, n. 1, p. 1-47, 1988.

HARVEY, D. I.; KELLARD, N. M.; MADSEN, J. B.; WOHAR, M. E. The Prebisch-Singer Hypothesis: four centuries of evidence. The Review of Economics and Statistics, v. 92, n. 2, p. 367-377, 2010.

KALDOR, N. Causes for the slow rate of growth in the United Kingdom. Cambridge: Cambridge University Press, 1966.

KRUGMAN, P. Differences in income elasticities and trends in real exchange rates. European Economic Review, v. 33, p. 1031-1054, 1989.

LIBÂNIO, G. A. Aggregate demand and the endogeneity of the natural rate of growth: evidence from Latin American economies. Cambridge Journal of Economics, v. 33, p. 967-984, 2009.

McCOMBIE, J. S. L. Criticism and defences of the balance-of-payments constrained growth model: some old, some new. PSL Quarterly Review, v. 64, p. 353-392, 2011.

MOLLIC, A. V.; FARIA, J. R.; ALBURQUERQUE, P. H.; LEÓN-LEDESMA M. A. Can globalization stop the decline in commodities terms of trade? Cambridge Journal of Economics, v. 32, p. 683-701, 2008.

MORENO-BRID, J. C. Capital flows, interest payments and the balance-ofpayments constrained growth model: a theoretical and empirical analysis. Metroeconomica, v. 54, n. 2, p. 356-365, 2003. 
MYRDAL. Teoria econômica e regiões subdesenvolvidas. Rio de Janeiro, 1960.

NELL, K. A generalised version of the balance of payments growth model: an application to neighbouring regions. International Review of Applied Economics, v. 17, n. 3, p. 249-267, 2003.

OCAMPO, J. A.; PARRA, M. Los términos de intercambio de los productos básicos en el siglo XX. Revista de la Cepal, n. 79, p. 7-37, 2003. The terms of trade for commodities since the mid $19^{\text {th }}$ century. Journal of Iberian and Latin America Economic history, p. 11-43, 2010.

OREIRO, J. L. Economia pós-keynesiana: origem, programa de pesquisa, questões resolvidas e desenvolvimentos futuros. Ensaios FEE, v. 32, n. 2, p. 283-312, 2011.

PALLEY. Pitfalls in the theory of growth. In: SETTERFIELD. The economics of demand-led growth: challenging the supply side vision of the long run. Cheltenham: Edward Elgar, 2002.

PORCILE, G.; CURADO, M.; CRUZ, M. Restrição externa e crescimento da economia brasileira. In: OREIRO, J. L.; PAULA, L. F.; BASÍlLIO, F. (Org.). Macroeconomia do desenvolvimento: ensaios sobre restrição externa, financiamento e política macroeconômica. Editora UFPE, 2012.

; LIMA, G. T. Tipo de cambio, empleo y crecimiento en un modelo con restricción externa. Investigación Económica, v. 65, p. 63-89, 2006.

PREBISCH, R. El desarrollo económico de la América Latina y algunos de sus principales problemas. Desarrollo Económico, v. 26, n. 103, p. 479-502, 1949.

. Commercial policy in the underdeveloped countries. The American Economic Review, v. 49, n. 2, p. 251-273, 1959.

. Hacia una dinámica del desarrollo latinoamericano. Cidade do México: Fondo de Cultura Económica, 1963, p. 28-36; 81-106.

(1951). Problemas teóricos y prácticos del crecimiento económico. Serie Conmemorativa del vigésimo quinto aniversario de la Cepal. Santiago do Chile: Comisión Económica para América Latina y el Caribe (Cepal), 1973.

REINHART, C.; WICKHAM, P. Commodity prices: cyclical weakness or Secular decline? IMF Staff papers, v. 41, n. 2, 1994.

RODRÍGUEZ, O. (2006). O estruturalismo latino-americano. Rio de Janeiro: Civilização Brasileira, 2009, p. 61-165.

RODRIK, D. The real exchange rate and economic growth. Brookings Papers on Economic Activity, p. 365-412, 2008. 
ROGOFF, K. The purchasing power Parity Puzzle. Journal of Economic Literature, v. 34, n. 2, p. 647-668, 1996.

ROMERO, J. P.; SILVEIRA, F.; JAYME JR, F.G. Brasil: cambio estructural y crecimiento con restricción de balanza de pagos. Revista de la Cepal, n. 105, 2011.

ROS, J. Latin America's trade and growth patterns, the China factor and Prebisch Nightmare. Journal of Globalization and Development, v. 3, n. 2, p. 1-16, 2013.

SAI-WING HO, P. Revisiting Prebisch and Singer: beyond the declining terms of trade thesis and on to technological capability development. Cambridge Journal of Economics, v. 36, p. 869-893, 2012.

SARKAR, P. Technical progress and the north-south terms of trade. Review of Development Economics, v. 5, n. 3, p. 433-443, 2001.

SERRANO, R.; PINILLA, V. The terms of trade for agricultural and food products, 1951-2000. Journal of Iberian and Latin American Economic History, v. 29, n. 2, 2011.

SETTERFIELD, M. The remarkable durability of Thirlwall's law. PSL Quarterly Review, v. 64, n. 2, p. 393-427, 2011.

SINGER, H. W. The distribution of gains between investing and borrowing countries. The American Economic Review, v. 40, n. 2, p. 473-485, 1950.

THIRLWALL, A. P. The balance of payments constraint as an explanation of international growth rate differences. BNL Quarterly Review, v. 32, p. 45-53, 1979.

. Foreign trade elasticities in centre-periphery models of growth and development. BNL Quarterly Review, v. 36, p. 249-261, 1983.

. Balance of payments constrained growth models: history and overview.

PSL Quarterly Review, v. 64, n. 259, p. 307-351, 2011.

; HUSSAIN, M. N. The balance of payments constraint, capital flows and growth rate differences between developing countries. Oxford Economic Papers, New Series, v. 34, n. 3, p. 498-510, 1982.

; BERGEVIN, J. Trends, cycles and asymmetries in the terms of trade of primary commodities from developed and less developed countries. World Development, v. 13, n. 7, p. 805-817, 1985.

ZANIAS, G. P. Testing for trends in the terms of trade between primary commodities and manufactured goods. Journal of Development Economics, v. 78, n. 1, 2005. 